\title{
LOS SIMPOSIOS DE PREDICCIÓN DEL ANTIGUO INM
}

\author{
Alejandro Roa Alonso ${ }^{(1)}$, Miguel Ángel García Couto ${ }^{(2)}$ \\ (1) AEMET, C/ Leonardo Prieto Castro 8, Madrid, aroaa@aemet.es \\ (2) AEMET, C/ Leonardo Prieto Castro 8, Madrid, migarciac@aemet.es
}

\section{INTRODUCCIÓN}

Durante los años 80 del siglo XX el Instituto Nacional de Meteorología (INM), predecesor de la actual Agencia Estatal de Meteorología abordó una profunda y ambiciosa transformación que cubrió todos los aspectos.

En los siguiente párrafos, extractados de "La evolución de la predicción meteorológica en el Instituto Nacional de Meteorología", de Ángel Rivera, Fermín Elizaga y Antonio Mestre, dentro de la publicación "El Instituto Nacional de Meteorología: Un reto tecnológico" (ver referencias), resumimos los principales aspectos de dicha transformación:

- "En primer lugar se acometió un Plan de Renovación Tecnológica, para el cual se encargó a un grupo de jóvenes meteorólogos que estudiaran los nuevos desarrollos tecnológicos, especialmente en materia de teledetección, así como las nuevas técnicas de predicción y vigilancia a corto y muy corto plazo. Para ello se visitaron diversos Servicios Meteorológicos de Europa y el de Estados Unidos. A partir de todo ello se diseñó el Sistema Integral de Vigilancia Meteorológica (SIVIM).

En octubre de 1982, cuando ya estaba diseñado en lo esencial el SIVIM, tuvieron lugar las trágicas inundaciones provocadas por la presa de Tous. El recién nombrado gobierno socialista tomó conciencia de inmediato de la necesidad de profundizar en la vigilancia y predicción de las lluvias intensas y dotó al INM de los fondos necesarios para sacar adelante el proyecto SIVIM.

El proyecto SIVIM implicó la instalación de un moderno sistema de recepción de satélites, el desarrollo de una red de radares meteorológicos y otra de estaciones automáticas, el despliegue de una red de detección de rayos y la adquisición de un superordenador para la explotación de modelos de predicción numérica. Además de lo anterior, se buscó una herramienta informática capaz de integrar de un modo eficaz y operativo las informaciones provenientes de todos estos sistemas. Dicha herramienta fue el sistema McIDAS, desarrollado en el Centro de Ciencia e Ingeniería Espacial (SSEC) de la Universidad de Wisconsin. Sistema que sigue funcionando en la actualidad.

Además de lo anterior, se procedió durante esta época a la creación del Sistema Nacional de Predicción. En su concepción se pretendía, además de una regionalización efectiva, la ampliación de la atención a muchos más usuarios que los tradicionales aeronáuticos y marítimos. Se crearon los Grupos de Predicción y Vigilancia (GPV), comenzando en 1986 por el de Palma de Mallorca y finalizando con los de Valladolid y Las Palmas en 1992, aunque posteriormente la predicción de Madrid y Castilla-La Mancha, que se hacía en el Centro Nacional de Predicción, se pasó al Centro Territorial de Madrid, creándose el undécimo y último GPV.

De este modo, a principios de los años 90 el Sistema Nacional de Predicción comenzaba a funcionar operativamente. Se creó un Área de Predicción que coordinaba todo el 
Sistema y de la que dependían el Servicio Nacional de Predicción, el Servicio de Técnicas de Análisis y Predicción y el Servicio de Predicción Numérica.

En esa época se pusieron en marcha los planes PREVIMET (Predicción y Vigilancia Meteorológica), antecesores del actual Plan Meteoalerta, primero el PREVIMET Mediterráneo, en 1987, luego el PREVIMET Galernas, en 1988, y por último el PREVIMET Nevadas, en 1992."

Es en el contexto descrito cuando se pusieron en marcha los Simposios Nacionales de Predictores, luego de Predicción, del Instituto Nacional de Meteorología. En la celebración de estos encuentros entre los profesionales del INM puso un gran empeño quien era entonces Subdirector de Predicción y Vigilancia, Alfonso Ascaso, siendo Manuel Bautista Director del Organismo entre 1986 y 1996, y un gran impulsor de su total renovación.

\section{EL PRIMER SIMPOSIO}

El Primer Simposio Nacional de Predictores (figura 1) tuvo lugar en el año 1989, probablemente en noviembre, aunque no hay constancia fidedigna de la fecha exacta. Se presentaron apenas 26 ponencias, a cargo de 25 autores, todos ellos personal del INM. Las ponencias se dividieron en tres sesiones:

- Sesión 1: Estudios sinópticos y mesoescálicos (9 ponencias)

- Sesión 2: Modelos y métodos numéricos (10 ponencias)

- Sesión 3: Técnicas y métodos operativos (7 ponencias)

Fig. 1.- Portada de la publicación del Primer Simposio del INM

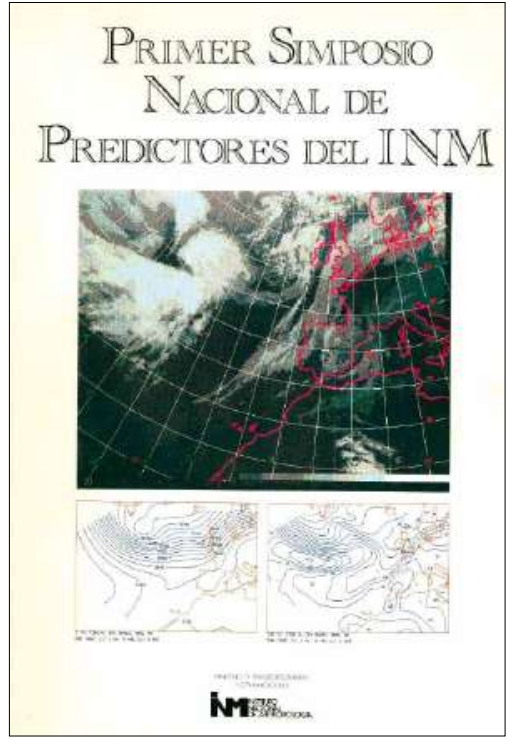

Cada una de las tres sesiones llevaba un texto introductorio a cargo del moderador de la sesión. Leyendo estos textos con casi treinta años de distancia se observa, por una parte, las enormes diferencias, sobre todo tecnológicas, con la actual Agencia Estatal de Meteorología, y por otra el gran entusiasmo que pusieron aquellas personas que renovaron por completo el servicio meteorológico español con un plan definido, así como su claridad de ideas, casi profética en algunos casos.

Como ejemplo de lo dicho, he aquí unos extractos del texto de Ángel Rivera, jefe del Servicio de Técnicas de Análisis y Predicción entonces, luego jefe del Área de Predicción, portavoz del INM y actualmente jubilado pero aún fascinado por la Meteorología, en su introducción a la primera sesión, dedicada a estudios sinópticos y mesoescálicos: 
_-Los famosos sucesos atmosféricos de 1982 y 1983 tanto en el Mediterráneo, Pirineos y País Vasco, como los trabajos pioneros del CMZ de Baleares en el terreno de los estudios mesoescálicos marcaron un punto de inflexión en las características de estos trabajos, así como también contribuyó a ello el uso intensivo de las imágenes de satélite que hacia 1983 podían explotarse ya rutinariamente".

_-Mirando al futuro quizá pueden señalarse ya dos factores que pueden marcar en gran manera el rumbo de las actividades de predicción. Por una parte la constatación de que "el Sur también existe". Quiero decir con ello que la mayoría de las situaciones atmosféricas que afectan a la Península Ibérica y al área Mediterránea están directamente influenciadas por África y las circulaciones subtropicales y puede que incluso tropicales. El otro factor es la mesoescala".

La segunda sesión, la dedicada a los modelos numéricos, fue moderada por Rosario (Charo) Díaz-Pabón, entonces jefa del Servicio de Predicción Numérica, luego Subdirectora General de Climatología, Investigación y Aplicaciones (Subdirección más tarde llamada de Programas Especiales e Investigación Climatológica), Adjunta a la Dirección General y actualmente también jubilada.

En su intervención, además de recordar la historia de los inicios de la modelización en el INM, dijo cosas como las siguientes:

-"El desarrollo de modelos de predicción inicializados con buenas técnicas de asimilación de datos, completados con técnicas de vigilancia [...] permite predecir sucesos meteorológicos adversos hasta 36 ó 48 horas".

-"Es necesario que los próximos esfuerzos se dirijan a adecuar la presentación de los resultados de la predicción numérica y a continuar mejorando la calidad de la misma, introduciendo nuevas parametrizaciones, aumentando la resolución, etc."

La tercera sesión, técnicas y métodos operativos, corrió a cargo de Ricardo Riosalido, entonces jefe de Sección del STAP, luego jefe de ese mismo Servicio, Subdirector General de Redes, Sistemas y Producción Meteorológica, Director de la Oficina de Programa del Cielo Único, Director de Producción e Infraestructuras al transformarse el INM en AEMET y actualmente en esa misma Dirección.

Extraemos de su introducción el siguiente párrafo, que puede resultar muy chocante hoy en día:

-"Otro aspecto que me gustaría destacar es cómo el acceso a los productos de los modelos numéricos (base para la predicción) va a cambiar sustancialmente. Hasta ahora, el predictor tenía que conformarse con un conjunto de campos muy limitados transmitidos vía facsímil. A partir de ahora tendrá un acceso inmediato a todo el conjunto de campos producidos por los diferentes modelos sin limitación alguna, es más, podrá manipularlos, presentarlos de diferente manera, combinarlos y calcular de una manera sencilla cualquier otro campo derivado que desee".

\section{EL SEGUNDO SIMPOSIO}

El Segundo Simposio Nacional de Predicción (figura 2) tuvo lugar un año después, entre el 20 y el 22 de noviembre de 1990. En esta ocasión hubo un total de 40 ponentes, 
entre autores principales y secundarios, todos menos uno personal del INM. Se presentaron 32 ponencias, divididas en tres sesiones similares a las del Primer Simposio:

- Sesión 1: Estudios sinópticos y mesoescálicos (10 ponencias)

- Sesión 2: Modelos numéricos y métodos objetivos (14 ponencias)

- Sesión 3: Técnicas y métodos operativos. Verificación (8 ponencias)

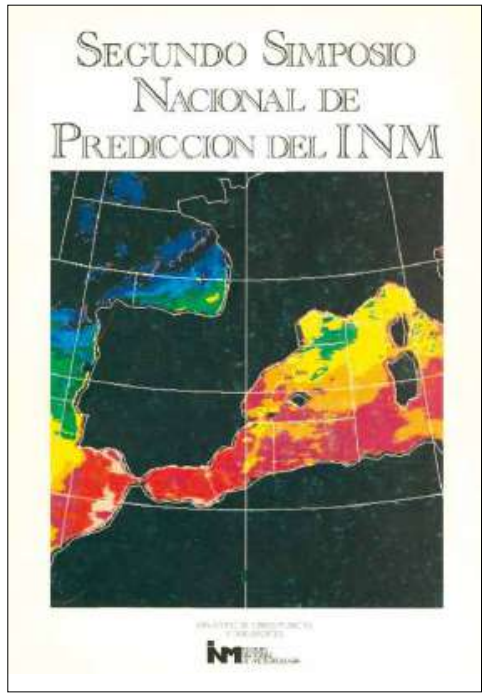

Fig. 2.- Portada de la publicación del Segundo Simposio del INM

\section{EL TERCER SIMPOSIO}

Tuvieron que transcurrir seis años hasta la convocatoria del Tercer Simposio Nacional de Predicción (figura 3), en abril de 1996. En esta ocasión se presentaron bastantes más ponencias, 71 en concreto, divididas en cinco sesiones:

- Sesión A: Estudios sinópticos y mesoescáli$\cos$ (17 ponencias)

- Sesión B: Modelos numéricos y métodos objetivos (16 ponencias)

- Sesión C: Procedimientos operativos de predicción, campañas especiales y verificación (14 ponencias)

- Sesión D: Estudios de caracterización de fenómenos meteorológicos (15 ponencias)

- Sesión E: PEMMOC/PYREX (9 ponencias)

Por lo que respecta a la sesión E, PEMMOC son las siglas del Programa de Estudios Meteorológicos del Mediterráneo Occidental, mientras que PYREX fue el "Experimento Pirenaico franco-español para el estudio de los efectos de la cordillera pirenaica sobre la

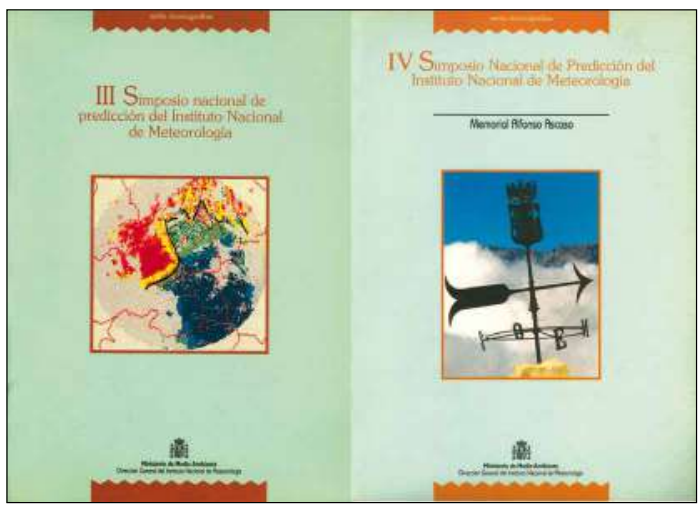
circulación atmosférica”, experimento que se desarrolló durante el año 1990. El número de ponentes fue de 82 , de los cuales 66 eran personal del INM y 16 pertenecían a otros organismos, universidades o servicios meteorológicos de otras naciones.

Figs. 3 y 4.- Portadas de las publicaciones del Tercer y Cuarto Simposios del INM 


\section{EL CUARTO SIMPOSIO}

El Cuarto Simposio Nacional de Predicción (figura 4) tuvo lugar tres años más tarde, en 1999. El número de ponencias presentadas ascendió en esta ocasión hasta 95, divididas en cuatro sesiones, la primera de ellas subdividida en dos, más una de posters. En la publicación correspondiente se incluyó, por vez primera, un índice de autores, un total de 112, de los que 96 eran trabajadores del propio INM. Las sesiones fueron las siguientes:

- Sesión AI: Estudios sinópticos y mesoescalares: casos de estudio (15)

- Sesión AII: Estudios sinópticos y mesoescalares: caracterización de fenómenos meteorológicos (15)

- Sesión B: Técnicas de análisis, diagnosis y predicción (12)

- Sesión C: Procedimientos operativos de predicción, campañas especiales, verificación y control de calidad (14)

- Sesión D: Modelos numéricos (12)

- Sesión P: Posters (27)

El Cuarto Simposio Nacional de Predicción fue dedicado a la memoria de Alfonso Ascaso, que había fallecido cuatro años antes. Alfonso Ascaso (1936-1995), fue director del Centro Meteorológico del Ebro (1973-84), Subdirector de Predicción y Climatología (1984-86), y por último Subdirector de Predicción y Vigilancia (1986-1995), tras la reordenación del INM. Fue un gran impulsor del Plan de Innovación Tecnológica, de la creación de los Grupos de Predicción y Vigilancia y de la celebración de los Simposios de Predicción, por lo que era de recibo que se dedicara uno a su memoria.

\section{EL QUINTO SIMPOSIO}

El Quinto Simposio Nacional de Predicción, último hasta la fecha, tuvo lugar entre el 20 y 23 de noviembre del año 2001. Se presentaron 91 ponencias, divididas en cinco sesiones. El total de ponentes fue de 98, de los cuales 87 eran personal del INM. En esta ocasión, atendiendo a las restricciones presupuestarias en materia editorial, en vez de un libro en papel con los trabajos completos, se publicó un folleto (figura 5) con el programa

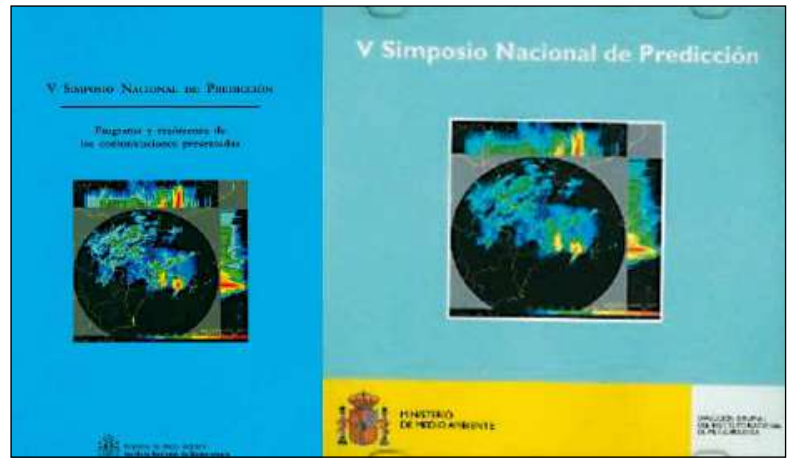

y resúmenes de las comunicaciones. Los trabajos completos se publicaron por vez primera en soporte electrónico, concretamente en un CD (figura 6) y en formatos doc de Word y .pdf. Las sesiones fueron las siguientes:

Figs. 5 y 6.- Portadas de las publicaciones, en papel y en formato electrónico del Quinto Simposio del INM 
- Sesión A: Casos de estudio (16 ponencias)

- Sesión B: Caracterización de fenómenos meteorológicos (14 ponencias)

- Sesión C: Técnicas de análisis, diagnosis y predicción (26 ponencias)

- Sesión D: Procedimientos operativos de predicción. Verificación (19 ponencias)

- Sesión E: Modelos numéricos (16 ponencias)

\section{DATOS GENERALES DE LOS CINCO SIMPOSIOS}

En la figura 7 presentamos un resumen de los números de ponentes y de ponencias, agrupados según diversos criterios, así como del número de páginas de las publicaciones de los cinco Simposios de Predicción del INM.

\begin{tabular}{|c|c|c|c|c|c|c|c|c|}
\hline & & & \multicolumn{6}{|c|}{ SIMPOSIO } \\
\hline & & & 1 & 11 & ill & N & v & conjunto 5 simposios \\
\hline \multicolumn{3}{|c|}{ Número de ponencias presentadas } & 26 & 32 & 71 & 95 & 91 & 315 \\
\hline \multirow{13}{*}{ Ponentes } & \multirow{7}{*}{...del INM } & Predicción / E+D & 15 & 23 & 55 & 68 & 56 & $129[0]$ \\
\hline & & Climatologia/A plicaciones & 3 & 0 & 1 & 5 & 9 & $14[0$ \\
\hline & & Observación/sse日 & 3 & 4 & 5 & 16 & 12 & 2010 \\
\hline & & Otros (usuarios, gestión, etc.) & 4 & 12 & 5 & 7 & 10 & $\left.291^{\circ}\right)$ \\
\hline & & Servicios centrales INM & 12 & 10 & 23 & 41 & 38 & 74 \\
\hline & & Servicios periféricos INM & 13 & 29 & 43 & 55 & 49 & 110 \\
\hline & & TOTAL ponentes del INM & 25 & 39 & 66 & 96 & 87 & 184 \\
\hline & \multirow{4}{*}{...no pertenecientes al INM } & Ámbito universitario & 0 & 1 & 9 & 7 & 5 & 20 \\
\hline & & Servicios meteo & 0 & 0 & 7 & 7 & 4 & 16 \\
\hline & & Otros & 0 & 0 & 0 & 2 & 2 & 4 \\
\hline & & TOTAL ponentes no INM & 0 & 1 & 15 & 16 & 11 & 40 \\
\hline & \multicolumn{2}{|c|}{ Ponentes de organismos ESPANNOLES } & 25 & 40 & 68 & 105 & 94 & 201 \\
\hline & \multicolumn{2}{|c|}{ Ponentes de arganismos NO ESPANOOLES } & 0 & 0 & 14 & 7 & 4 & 23 \\
\hline & \multicolumn{2}{|c|}{ TOTAL PONENTES } & 25 & 40 & 82 & 112 & 98 & 224 \\
\hline \multicolumn{3}{|c|}{ Número de páglnas de la publicación $\left(^{* *}\right)$} & 322 & 458 & 634 & 672 & 475 & 2561 \\
\hline \multicolumn{9}{|c|}{ (*) Algunos autores cambiaron de filiación de un simposio a ctro; por eso, en el conjunto de simposios su filiación puede figurar varias veces contabilizacia en las casillas seña ladas } \\
\hline \multicolumn{6}{|c|}{$(* *)$ El V Simposio se editb en formato CD; el nùmefo de páginas corres pande a la suma de päginas de todos los pdf que lo integran } & & & \\
\hline
\end{tabular}

Fig. 7.- Cuadro resumen de los cinco Simposios de Predicción

A modo de curiosidad, las siguientes personas fueron las únicas que presentaron ponencias en los cinco Simposios:

- Gabriel BUENDÍA MOYA

- José Antonio GARCÍA-MOYA ZAPATA

- Agustín JANSÁ CLAR

- Francisco MARTÍN LEÓN

- Ernesto RODRÍGUEZ CAMINO

El mayor número de ponencias fue presentado por:

- Agustín JANSÁ CLAR (22 ponencias)

- José Antonio GARCÍA-MOYA (19 ponencias)

- Francisco MARTÍN LEÓN (18 ponencias)

- Ernesto RODRÍGUEZ CAMINO (17 ponencias)

- Ricardo RIOSALIDO ALONSO (14 ponencias)

Y, para finalizar, si solo nos fijamos en los primeros firmantes de cada artículo (autores principales), el mayor número de ponencias presentadas como autores principales corresponde a las siguientes personas: 
- José Antonio GARCÍA-MOYA (10 ponencias)

- José Luis CAMACHO RUIZ (8 ponencias)

- Francisco MARTÍN LEÓN (8 ponencias)

- Ernesto RODRÍGUEZ CAMINO (7 ponencias)

\section{Referencias}

- INSTITUTO NACIONAL DE METEOROLOGÍA, 1989. Primer Simposio Nacional de Predictores. INM, Madrid.

- INSTITUTO NACIONAL DE METEOROLOGÍA, 1990. Segundo Simposio Nacional de Predicción. INM, Madrid. ISBN 84-7837-060-9.

- INSTITUTO NACIONAL DE METEOROLOGÍA, 1992. Tercer Simposio Nacional de Predicción. INM, Madrid. ISBN 84-498-0233-4.

- INSTITUTO NACIONAL DE METEOROLOGÍA, 1996. Cuarto Simposio Nacional de Predicción. INM, Madrid. ISBN 84-8320-083-X.

- INSTITUTO NACIONAL DE METEOROLOGÍA, 2001. Quinto Simposio Nacional de Predicción. INM, Madrid. ISBN 84-8320-192-5.

- RIVERA, Á., ELIZAGA, F. y MESTRE, A., 2004. "La evolución de la predicción meteorológica en el Instituto Nacional de Meteorología". En: "El Instituto Nacional de Meteorología: Un reto tecnológico". INM, Madrid. ISBN 84-8320-266-2. 